\section{LONDON DENTAL STUDENTS TREAT 1,500 IN GHANA}

Thirty-one dental students from King's College have completed a ten-day relief effort for a community in Ghana, in collaboration with Global Medical Brigades.

Global Medical Brigades works with licensed medical professionals and community health workers in Honduras, Ghana and Panama to provide comprehensive health services in rural communities with limited access to healthcare.

The dental students were led by Aws Alani from Newcastle, Gareth Calvert from Glasgow and Alon Livny from Jerusalem, with Nikita Patel coordinating the medical and dental teams.

The group landed in the Ghanaian capital, Accra, on 17 August 2012 before travelling to the rural fishing community of Narkwa with donated dental equipment.

Reporting to the $B D J$ after the trip, Dr Calvert said: 'Global
Brigades have newly chosen this community because of its population size, little infrastructure, significant distance to a health care establishment and limited access through challenging terrain and single-track road.'

The team set up in Narkwa's school, one of the only purpose built structures in the community. The 27 third and fourth year undergraduates divided the rooms into triage, treatment, sterilisation and oral health promotion and treated 1,500 people without electricity or running water. The students also visited homes in the community to reinforce general health information.

'All the Global Brigaders, local translators and community members shared an unforgettable experience,' said Dr Calvert. A second trip to Narkwa by Global Bridges is planned for as early as this Christmas.

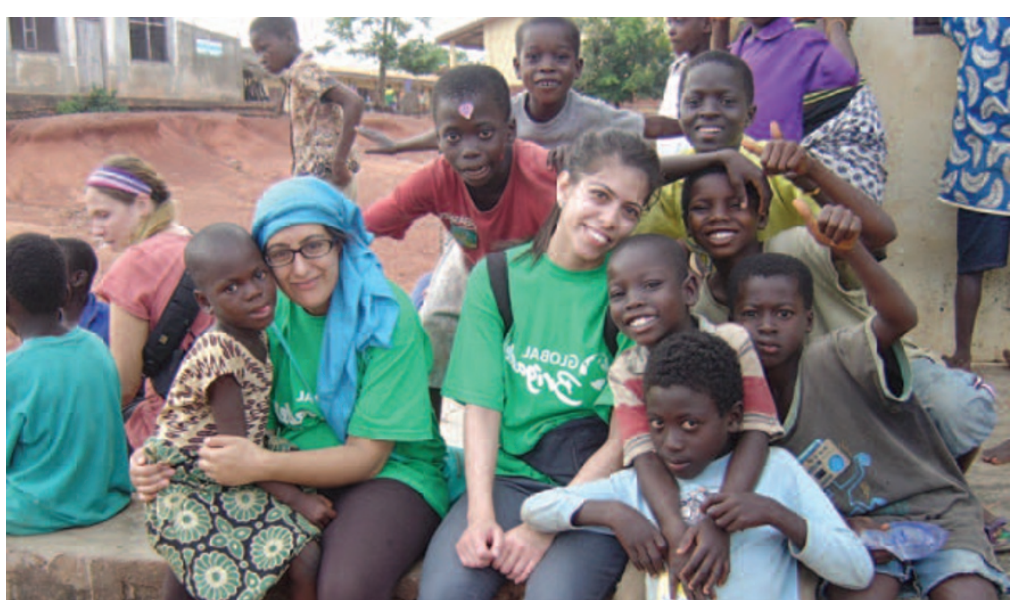

Dental Global Brigaders in Narkwa, Ghana

\section{DENTIST HANDS OVER PRACTICE TO HIS STAFF}

Philip Guest, who runs a well established dental practice near Wrexham, has become the first dental practice owner to transfer the ownership of his business to its employees. Gwersyllt Dental Care near Wrexham is now part of the Future Health Partnership.

The Future Health Partnership enables the whole dental team to have a stake in the way their practice is managed and run, as it is their own business.

Dr Guest explained: 'Employee ownership is something which I have been aware of for many years in

\section{MILLIONS LOST THROUGH BAD REVIEWS ONLINE}

According to a UK-based 'online reputation management agency', UK dentists are losing out on millions of pounds due to fake reviews on the Internet

Review sites such as Qype, Yelp and Tripadvisor encourage consumers to write reviews but do not authenticate them or attempt to prove that the reviewer is genuine. It is estimated that one in ten reviews are fake.

The Internet is often the first port of call for people looking for a dentist or someone who can whiten their teeth or give them a 'smile makeover'.

'A single bad review can ruin the chances of gaining new customers and create a longstanding, horrible word of mouth campaign offline,' said Mark Hall, managing director of Got Juice.

A recent letter to the $B D J$ (Unjustified vindictiveness; BDJ 2012; 213: 147) expressed anger and frustration at the comments left by a 'vindictive patient' on the website NHS Choices, saying that the comments are 'easily visible to any prospective new patient and only two clicks away when you Google our practice and my name'. The dental practice in question then enlisted the help of loyal patients to add their own positive comments and 'drown' the adverse comments in a 'sea of praise about 18 clicks deep'.

Mr Hall, whose company focuses on helping businesses gain positive reviews and to fight back and remove unwanted negative press from review sites, says that the UK defamation law is difficult to enforce as the vast majority of review sites are based overseas and do not acknowledge the UK law.

'If your business receives a negative review or mention it is very important to respond to the customer online, always remain calm and do not take it personally. A good response would be to offer an apology and an invitation to discuss things in more detail,' said Mr Hall. other sectors. When I heard about Future Health, I realised that there was an immediate fit for myself, my employees and our patients. I have a real sense of doing the right thing and giving something back to everybody who is associated with Gwersyllt Dental Care'.

Synonymous with businesses such as John Lewis Partnership, the Future Health Partnership is the first employee-owned company to successfully emulate the model for the dental sector.

The adoption of the Future Health model is likely to appeal most to dental practice owners who are disillusioned with the increasing burdens of practice management and administration, allowing them to refocus on improving patient care and enhancing the working environment for all staff, as well as benefitting financially from the transfer of ownership. 